\title{
REPRESENTAÇÃO DO CORPO NA RELAÇÃO CONSIGO MESMA APÓS MASTECTOMIÁ
}

\author{
Maria de Lourdes da Silva Marques Ferreira ${ }^{2}$ \\ Marli Villela Mamede
}

Ferreira MLSM, Mamede MV. Representação do corpo na relação consigo mesma após mastectomia. Rev Latino-am Enfermagem 2003 maio-junho; 11(3):299-304.

Esta pesquisa objetivou compreender como a mulher mastectomizada representa o seu corpo nas relações consigo mesma. O referencial teórico-metodológico foram as representações sociais. Foram entrevistadas, no domicílio, dez mulheres mastectomizadas, no sétimo dia pós-alta e uma vez por mês, durante quatro meses de pós-operatório. Os conteúdos da representação do corpo consigo mesma convergiram para quatro unidades de significação: a) corpos mutilados, cuja percepção foi demonstrada de diferentes formas; b) sensação de impotência em diversos momentos do período pós-operatório; c) dor e limitação, principalmente no início de sua recuperação; d) cuidado com o corpo. Foi possível entender que o princípio do cuidado de si para as mulheres tomou a forma de uma atitude, desenvolvida em práticas que foram refletidas e ensinadas como um processo contínuo após a cirurgia. A percepção da relação de corpo/físico/mente/espírito permearam, todos os momentos, sua vivência. Os resultados oferecem importantes elementos para reflexão quanto à assistência às mulheres mastectomizadas.

DESCRITORES: corpo humano, mastectomia, auto-imagem

\section{BODY REPRESENTATION IN THE RELATION WITH THE SELF AFTER MASTECTOMY}

This research aimed to understand how the mastectomized woman represents her body in the relations with herself. Social representations were used as a theoretical-methodological reference base. Ten mastectomized women were interviewed at their homes on the seventh day after leaving the hospital and once a month during four postoperative months. The contents of the body representation to the self converged towards four meaning units: a) mutilated bodies, the perception of which was demonstrated in difference ways; b) feeling of impotence at different times in the postoperative period; $c$ ) pain and limitation, mainly at the beginning of recovery; $d$ ) care with the body. It could be understood that, for the women, the beginning of self-care took the form of an attitude that was developed in practices reflected and taught as a continuous process after the surgery. The perception of the body/constitution/mind/spirit relation permeated every moment of their existence. The results offer important elements for reflection in relation to the assistance to mastectomized women.

DESCRIPTORS: human body, mastectomy, self-image

\section{REPRESENTACIÓN DEL CUERPO EN LA RELACIÓN CONSIGO MISMA DESPUÉS DE LA MASTECTOMÍA}

Esta investigación tuvo como objetivo entender cómo la mujer mastectomizada representa su cuerpo en las relaciones consigo misma. La teoría de las representaciones sociales se adoptó como referencial teórico metodológico. Se entrevistaron en su hogar diez mujeres mastectomizadas en el séptimo día después de salir del hospital y una vez por mes durante cuatro meses del postoperatorio. Los contenidos de la representación del cuerpo evidenciaron cuatro unidades de importancia: a) cuerpo mutilado, cuya percepción se demostró de diferentes maneras; b) sensación de impotencia; c) dolor y limitación, principalmente al principio de su recuperación; d) cuidado con el cuerpo enfermo. El principio del cuidado de sí para las mujeres tomó la forma de una actitud, desarrollada en prácticas que se reflexionaron y enseñaron como un proceso continuo después de la cirugía. La percepción y la relación de cuerpo/físico/mente/espíritu penetraron en todos los momentos de su existencia. Los resultados ofrecen importantes elementos para la reflexión en relación a la atención de la mujeres mastectomizadas.

DESCRIPTORES: cuerpo humano, mastectomía, autoimagen

\footnotetext{
${ }^{1}$ Este trabalho é parte da Tese de Doutoramento apresentada à Escola de Enfermagem de Ribeirão Preto da Universidade de São Paulo, em agosto de 1999. Apresentada no VII Colóquio Panamericano de Enfermería - outubro de 2000 - Bogotá - Colômbia e 52ํㅡㄴ Congresso Brasileiro de Enfermagem - outubro de 2000 - Recife - PE - Brasil; ${ }^{2}$ Professor Assistente Doutor da Faculdade de Medicina da Universidade Estadual Paulista - Botucatu, e-mail: malusa@connectmed.com.br; ${ }^{3}$ Professor Titular da Escola de Enfermagem de Ribeirão Preto da Universidade de São Paulo, Centro Colaborador da OMS para o desenvolvimento da pesquisa em enfermagem
} 
INTRODUÇÃO

$\boldsymbol{A}$ mastectomia é um dos tratamentos a que a maioria das mulheres com câncer de mama é submetida, e os seus resultados poderão comprometê-las física, emocional e socialmente. A mutilação dela decorrente favorece o surgimento de muitas questões na vida das mulheres, especialmente aquelas relacionadas à imagem corporal. Como a mulher percebe e lida com essa nova imagem, como isso afeta a sua existência apresentamse como forma de inquietações para os profissionais que se propõem prestar uma assistência integral.

Ao receber um diagnóstico de câncer de mama, a mulher passa a ter muitas dúvidas e questionamentos, devido ao estigma de doença terminal e que leva a muito sofrimento e morte.

Como em outras doenças estigmatizantes, o câncer de mama é, ainda, muito temido em nosso século, isso porque, na contemporaneidade, vem crescendo impetuosamente.

Diante da confirmação do diagnóstico, a mulher passa a ter dois tipos de problemas: o medo do câncer propriamente dito, e da mutilação de um órgão que representa a maternidade, a estética e a sexualidade feminina $^{(1)}$. Na atribuição de significados para as mamas na cultura ocidental, é ressaltada sua importância como atributo físico e psíquico para o organismo feminino. Além de seu papel importante na vivência e na demonstração da feminilidade, as mamas são, também, órgãos que produzem e carregam o leite, uma das fontes simbólicas da vida e da maternidade ${ }^{(2)}$. A alteração da estética e imagem corporal são aspectos a serem considerados na prática profissional, especialmente quando se pensa em uma assistência preocupada, também, com a dimensão psicossocial.

A amputação de qualquer parte externa ou mesmo interna do corpo é traumática, podendo produzir mudança radical na aparência, e, assim, a auto-imagem corporal deve ser ajustada a essa nova situação ${ }^{(3)}$.

Nessa nova realidade, ao observar que as mulheres passam a enfrentar problemas ligados à mutilação de seu corpo, surgem, para nós, inquietações sobre como assistir a essa clientela de forma integral, especialmente no retorno ao seu lar, ao seu cotidiano, pois ainda não há clareza como esse processo é vivido e interpretado por elas. Questiona-se: Como a mulher tem apreendido a experiência de ser mastectomizada? Quais as transformações que ocorrem? Como lidar com a nova realidade e novas perspectivas?

O retorno para casa e para a sociedade, após uma mastectomia, pode ser acompanhado por grandes dificuldades ${ }^{(4)}$.

Após a cirurgia, as mulheres têm como preocupação a continuidade do tratamento e a reabilitação, surgem questões relativas à reelaboração da auto-estima e da imagem corporal, necessidade de suporte social e de autocuidado ${ }^{(5)}$. O "já-ter-sido-mastectomizada" revela que as mulheres percorrem trajetórias diferentes quando retornam aos seus familiares e à condução de suas vidas. Esse retorno possibilita uma reflexão sobre o vivido, sintetizado pelos sujeitos do referido estudo na frase: "foi tudo muito difícil, não foi fácil’(6).

O conhecimento do significado da mutilação para as mulheres que a vivenciam, precisará ficar claro para os profissionais, para que eles possam reconhecer a representação disso no contexto de vida das mulheres, na ocasião da alta hospitalar e ao retornarem para casa, agora mastectomizadas.

Diante dessas inquietações, este trabalho tem, como objetivo, compreender como a mulher representa o seu corpo após a mastectomia, quando retorna para casa, nas relações consigo mesma.

\section{REFERENCIAL TEÓRICO METODOLÓGICO}

A representação social foi o referencial do presente estudo, pois ele permite descrever um conjunto de proposições e explicações originadas na vida cotidiana, no curso de comunicações interpessoais. As representações são o equivalente em nossa sociedade, aos mitos e sistemas de crenças das sociedades tradicionais; podem, ainda, ser vistas como a versão contemporânea do senso comum ${ }^{(7)}$.

A mediação privilegiada para a compreensão das representações sociais é a linguagem. Para a comunicação da vida cotidiana, a palavra é fundamental. Pela vinculação dialética com a realidade, a compreensão da fala exige, ao mesmo tempo, a compreensão das relações sociais que ela expressa ${ }^{(8)}$.

Por representar uma possibilidade de compreensão da situação de vida das mulheres pósmastectomia, pelo conhecimento mais profundo das suas vivências na relação consigo mesmas, quando retornaram 
ao seu cotidiano, optou-se pelo "estudo de caso" como modalidade metodológica.

Uma vez que o estudo de caso não parte de uma visão pré-determinada da realidade, este possibilitou apreender os aspectos ricos e imprevistos da representação social de corpo.

Para análise das descrições obtidas por meio das entrevistas, buscando pela representação do corpo na relação consigo mesma após a mastectomia, utilizou-se a técnica de análise de conteúdo ${ }^{(8)}$.

Após a aprovação da pesquisa pelo Comitê de Ética em Pesquisa do Hospital das Clínicas (HC) da Faculdade de Medicina de Botucatu -UNESP, foi iniciada a coleta de dados. Os sujeitos do estudo constituiram-se de dez mulheres residentes em Botucatu ou cidades vizinhas, em um raio de até $100 \mathrm{~km}$ de distância, que realizaram mastectomia radical ou conservadora ou quadrantectomia, por câncer de mama.

O período da coleta de dados foi de fevereiro a julho de 1998, ocasião em que a pesquisadora participou da assistência pré e pós-operatória, estabelecendo, assim, os primeiros contatos para, posteriormente, realizar a visita domiciliar. Para as mulheres que aceitaram participar do estudo, foi solicitada a assinatura do termo de consentimento livre e esclarecido do paciente.

Foram realizadas entrevistas e observações no domicílio da mulher, no sétimo dia pós-alta, e uma vez por mês, nos primeiros quatro meses decorridos da cirurgia. Para as mulheres que apresentaram complicações cirúrgicas, foram realizadas visitas domiciliares de acordo com as necessidades de cada caso, além das previamente definidas.

Para compreender o cotidiano da mulher mastectomizada, as representações que fazem do seu corpo após a mastectomia, as entrevistas nortearam-se com questões que possibilitassem obter descrições sobre seu retorno para casa:

- Como está sendo para você voltar para casa?

- Como é que você se sente com o corpo atual?

As entrevistas foram escritas imediatamente após a visita, ao sair da residência, para que não houvesse perda dos dados, uma vez que não foi utilizado gravador. A decisão de não realizar a gravação das entrevistas deuse pelo fato de acreditar que o gravador, se utilizado no domicilio, poderia inibir a espontaneidade da mulher. Para a análise dos dados deste estudo, procuramos ordenar o conteúdo das entrevistas por meio de releituras do material e organização dos relatos e das observações. Essa fase facilitou um mapeamento horizontal das descrições.

Da leitura exaustiva e repetida dos textos, apreendemos estruturas de relevância dos atores sociais e idéias centrais do tema em foco. Essa atividade nos auxiliou no estabelecimento das categorias empíricas, confrontando-as com as categorias analíticas teoricamente estabelecidas como balizas da investigação, buscando as relações dialéticas entre ambas. A seguir, recortamos cada entrevista em termos de unidade de registro referenciada como tópicos de informações ou como temas. Essa fase permitiu-nos a construção de um mapa transversal das descobertas.

As duas etapas anteriores nos possibilitaram fazer uma inflexão sobre o material empírico, o nosso ponto de partida e de chegada da interpretação. Esse movimento incessante, do empírico para o teórico e vice-versa, do concreto para o abstrato, entre o particular e o geral, mostrou-se com um verdadeiro movimento dialético, visando ao concreto pensado ${ }^{(8)}$.

\section{ANÁLISE E DISCUSSÃO DOS DADOS}

Após a leitura exaustiva dos conteúdos das entrevistas e notas de campo, foi possível organizar as unidades temáticas para análise, construindo-se as representações do corpo para as mulheres mastectomizadas.

Na relação consigo mesmas após mastectomia, as mulheres representam um corpo mutilado, experimentam sensação de impotência, dor e limitação, ao mesmo tempo percebem que esse corpo necessita de cuidados.

A mutilação do corpo foi representada pelas mulheres como perda de pedaços, percepção que têm de seu corpo atual, alterado e estranho, como mostram os relatos: Tira um pedaço do corpo da gente; Me senti estranha depois da cirurgia.

Ao configurarem o seu corpo como estando mutilado, fazem-no identificando sentimentos de tristeza, estranheza e preocupação com a evolução de seu pósoperatório.

Os padrões que a pessoa, com atributos de um estigma, incorporou da sociedade maior, torna-a intimamente susceptível ao que os outros vêem como seu defeito, levando-a a concordar que, na verdade, ela ficou 
abaixo do que realmente deveria $\operatorname{ser}^{(9)}$.

A identificação de um corpo mutilado dá-se pela percepção que ela tem de seu corpo atual, alterado e diferente, principalmente nas situações em que o observa, como nos momentos em que fica defronte ao espelho e quando está despida: Me sinto estranha, sinto falta da mama quando olho no espelho...; Quando a gente tira a roupa e vê que está sem a mama, é duro.

Elas revelam a necessidade de recuperar o espaço corporal perdido e referem à cirurgia plástica como possibilidade, reconhecendo que a imagem de um corpo perfeito já não existe: Não consigo parar de pensar na plástica; A gente nasce perfeito e morre com defeito.

O que a mulher aprendeu durante toda vida sobre a estética corporal é que o corpo feminino constitui-se por alguns caracteres secundários, e um deles é representado pelas mamas. Ao se submeter à mastectomia, acaba por perceber com estranheza o seu corpo.

Para algumas mulheres, a preocupação se dá pela percepção da assimetria do corpo e visibilidade da cirurgia. Para outras, a cirurgia é representada como um ato agressivo. Os depoimentos mostram: Me sinto torta com dificuldades para andar; É duro porque fica visível; Me arrancaram a mama.

A imagem corporal, sendo uma das experiências básicas na vida de qualquer um, traz traços característicos de toda a vida. A pessoa, ao perder parte de seu corpo, apresenta modificação do modelo postural, com alteração de toda a mobilidade do organismo ${ }^{(10)}$.

A mulher, ao perder a mama, apresenta modificações do modelo postural e percebe comprometimento na beleza física. A partir da cirurgia, tomam consciência da posição que a mama tem no contexto corporal e sociocultural, como evidencia o depoimento: na mama a gente nunca pensa e, quando perde, parece que perde o corpo todo, aí a gente se conscientiza da importância dela para o corpo.

Ao representarem o corpo como mutilado, conferido pela perda da mama, revelam que a incorporação da modificação corporal se dá por uma adaptação contínua e gradativa. A mastectomia desconstrói a imagem corporal de maneira abrupta. No entanto, essa imagem corporal e auto-estima são construídas pelas experiências acumuladas ao longo da vida. Portanto, a mulher mastectomizada necessita de um tempo para assimilação e incorporação dessa nova imagem corporal ${ }^{(5)}$. O corpo, em sua inteireza, como certas regiões dele, pode ficar sujeito a críticas por se afastar do ideal esperado, o qual é um produto do valor conferido pela sociedade às diferentes medidas do físico feminino ${ }^{(11)}$.

A sensação de impotência identificada pelas mulheres foi representada pela impossibilidade de mudar a indicação da mastectomia, de decidir sobre o seu próprio destino, de afastar o medo e probabilidade de recorrência do câncer, de ser portadora de uma doença considerada incurável. Alguns depoimentos retratam a sensação de impotência: Não tem jeito de fugir da cirurgia; Eu tenho medo do câncer porque ele pode ir para outro lugar do corpo; Vocês façam o que acharem melhor, vocês é que sabem; Fico só pensando na doença.

Em situação de doença, como o câncer de mama, e de ser submetida à cirurgia, além de ficarem impossibilitadas de cuidarem de suas famílias, passam a viver, muitas vezes, numa relação de dependência de outros para o cuidado consigo mesmas, o que, para muitas das mulheres estudadas, foi motivo suficiente para gerar sentimentos de impotência em suas vidas: Me aposentei proporcional para cuidar do meu filho pequeno que precisava de mim, e hoje, ficar em casa e ainda assim é duro, a gente se pergunta por que é que a gente tem que passar por tudo isso.

A expressão desses sentimentos nem sempre é facilmente verbalizadas, e os mitos, os ditados populares são um instrumento utilizado como metáforas para expressar dimensões profundas do humano que se tornam difíceis de serem traduzidas na linguagem conceitual ${ }^{(12)}$.

A profundidade do sentimento gerado em relação à sensação de impotência para decidir sobre o destino de seu corpo é revelada no depoimento: Minha mãe que dizia que a gente amarra o cavalo onde o patrão manda, então, se os médicos falarem que precisa da quimioterapia para matar a doença, a gente faz.

Na luta contra a doença, as mulheres perceberam que a situação vivenciada não dependia somente de si mesmas, como evidencia o depoimento: Aconteceu e eu não pude fazer nada.

O impacto do retorno para casa após a mastectomia transforma-se em sensação de impotência: Quando a gente chega em casa, vê que está sem a mama e que não tem jeito.

Decorrido um tempo maior de pós-operatório, as mulheres deparam-se com a necessidade de conformarse com a realidade: A gente acaba se acostumando porque não tem jeito de fazer nada; Conforme o tempo passa, a gente se conforma mais. 
Uma das mais notáveis características do homem como animal e que o caracteriza de certa forma, é a plasticidade de seu organismo, capaz de permitir a ele as mais diversas adaptações. Todas as experiências do homem são mensagens percebidas por intermédio dos sentidos e devem ser decodificadas. Nota-se, no presente estudo, que as mulheres, ao verbalizarem a necessidade de conformar-se ao corpo, como se apresenta no momento vivenciado, sinalizam a plasticidade ${ }^{(13)}$ : Não tirei a mama toda, e também não sou mais mocinha, então me conformei; Já não sou brotinho, não tenho marido, então tá bom.

A sensação de impotência sentida pelas mulheres estudadas em relação aos corpos configurados como objeto que se manipulam, se modelam, se treinam, obedecem e respondem, representa a definição que diz: o corpo consiste em objeto ora de submissão e utilização, ora de funcionamento e explicação: corpo útil, corpo inteligível. A noção de docilidade que une ao corpo analisável, manipulável, é que o corpo dócil pode ser submetido, utilizado, transformado e aperfeiçoado. O corpo humano entra em uma maquinaria de poder que 0 esquadrinha, o desarticula e o recompõe ${ }^{(14)}$.

As mulheres estudadas relataram que, quando estavam internadas, acreditavam que a situação de dependência dos outros para se cuidarem fosse normal, naquela situação em particular, e que, ao chegarem a casa, conseguiriam ser mais ativas e assumiriam normalmente os seus papéis domésticos, cuidados com os filhos e marido. No entanto, a realidade foi outra, começaram a perceber as dificuldades a serem enfrentadas, como dor e limitações: Ao chegar a casa me deparei com o problema de não poder fazer todos os serviços de casa.

As mulheres identificaram justificativas no próprio corpo, e a dor e a limitação foram queixas e sintomas que passaram a conviver em diferentes momentos no período pós-operatório: O braço, se esforçar, dói, ele está muito inchado. O corpo que dói passa a ser representado como uma perturbação física: Sinto muita dor no braço.

Para algumas mulheres, a dor e limitação extrapolam o aspecto físico, e outras percebem a dor fantasma. Os relatos evidenciam: A gente sente coisa que não sabe se é físico ou psicológico; Senti dor no mamilo da mama que tirou.

A dor fantasma diz que o ser humano está acostumado a ter um corpo completo, e, com a amputação, passa a enfrentar uma nova situação, mas, como reluta em aceitá-la, tenta manter a integridade de seu corpo, daí aparecer o membro fantasma ${ }^{(10)}$.

Em se tratando da mama amputada, a sensaçãofantasma pode representar uma tentativa de conservar as qualidades femininas e sexuais para a mulher ${ }^{(15)}$.

Uma vez realizada a mastectomia, as mulheres representam o corpo como frágil, ameaçado e que necessita de cuidados. Essa necessidade de cuidados com o corpo somente surge quando a existência de alguém, de alguma coisa, tem importância para a pessoa. Passa, então, a dedicar-se a esse alguém/coisa, desprovindo-se a participar de seu destino, de suas buscas, de seus sofrimentos, de seus sucessos, enfim, de sua vida ${ }^{(12)}$.

No período pós-operatório imediato, a própria incisão e a presença de drenos denunciam a necessidade de cuidados: Estou me cuidando, faço a limpeza do corte, lavo bem. Preocupam-se com a vestimenta ou disfarces e com o braço homolateral à cirurgia: Agora tenho que cuidar de mim; Coloquei uma espuma para disfarçar. Tenho que fazer fisioterapia para o braço não inchar.

Cuidar das coisas, do corpo, de si implica ter intimidades, senti-las, acolhê-las, respeitá-las, dar-lhes sossego e repouso.

Cuidar é entrar em sintonia com, auscultar-lhes o ritmo e afirmar-se com ele. A razão analítico-instrumental abre caminho para a razão cordial, ou seja, para o espírito de delicadeza e o sentimento profundo ${ }^{(12)}$. Assim, o sentimento de cuidar-se de si é despertado no indivíduo quando descobre que está em estado de necessidade. $\mathrm{Na}$ arte da existência, encontra-se o princípio segundo o qual é preciso ter cuidados consigo ${ }^{(14)}$.

Ao se preocuparem consigo mesmas, as mulheres procuram meios de se cuidarem buscando as soluções consideradas as mais adequadas para melhorar a sua imagem corporal, como expressam: Com a prótese, a gente se sente mulher de novo.

O corpo com o qual as mulheres estudadas tiveram que se ocupar, representou-lhes não mais ser um corpo jovem do qual se cuida por meio de outros investimentos, mas um corpo frágil e ameaçado. $\mathrm{Na}$ arte do cuidar, é preciso ajuda do outro, pois os cuidados que se têm consigo mesmo, intensifica-se nas relações sociais ${ }^{(14)}$.

$\mathrm{Na}$ convivência com as mulheres durante os primeiros meses de pós-cirurgia por câncer de mama, em vários momentos, foi possível observar que elas procuravam se auto-afirmarem em seu próprio valor, buscando ações que as singularizavam e que lhes permitiam prevalecer 
sobre os outros, sem que tivessem de atribuir uma grande importância às suas vidas privadas ou às relações de si para consigo. A representação de um corpo mutilado que dói, restringe, constrange, necessitou ser cuidado e velado por elas mesmas.

Tais exigências foram expressas dentro de contextos que caracterizavam o desenvolvimento daquilo que chamaria de "cultura de $\mathrm{si}^{\text {"(14) }}$, na qual foram intensificadas e valorizadas as relações, das mulheres mastectomizadas, de si para consigo mesmas.

Nesse sentido, reconheceram que era preciso "ter cuidados consigo", é esse princípio do cuidado de si que fundamenta a sua necessidade, comanda o seu desenvolvimento e organiza a sua prática ${ }^{(14)}$.

\section{CONSIDERAÇÕES FINAIS}

Foi possível apreender que grande parte da trajetória empreendida pelas mulheres durante o período da coleta de dados para o presente estudo foi dedicado ao "ocupar-se consigo mesmas", representou o treinamento físico e espiritual para o cuidado delas próprias e de suas próprias almas, a fim de situarem-se como seres humanos compostos de uma integralidade, apesar de apresentarem uma mutilação física. Foi possível entender

\section{REFERÊNCIAS BIBLIOGRÁFICAS}

1. Tarricone SOP. Aspectos emocionais da mulher submetida a mastectomia no pós-operatório: subsídios para intervenção psicológica. [dissertação]. São Paulo (SP): Pontifícia Universidade Católica; 1992.

2. Krynski S. Reações psicológicas e psicopatológicas relacionadas à cirurgia da mama. Bol CEPP; 1986; 4(2):5965.

3. Barbosa AMS. Viagem ao vale da morte: estudo psicológico sobre mulheres mastectomizadas por câncer de mama.[dissertação]. São Paulo (SP): Instituto de Psicologia/ USP; 1989

4. Fernandes AFC. O cotidiano da mulher com câncer de mama. Fortaleza (CE): Fundação Cearense de Pesquisa e Cultura; 1997.

5. Silva RM, Mamede MV. O conviver com a mastectomia. Fortaleza (CE): UFC; 1998.

6. Malvezzi GM. A mastectomia em seu ir se mostrando à mulher que a vivencia. [dissertação]. Ribeirão Preto (SP): Escola de Enfermagem de Ribeirão Preto/USP; 1996.

7. Sá CP. Núcleo central das representações sociais. Rio de Janeiro (RJ): Vozes; 1996. que o princípio do cuidado de si tomou a forma de uma atitude, de uma maneira de comportar-se, impregnou nelas novas formas de viver, desenvolvidas em práticas que foram refletidas e ensinadas. Estas práticas foram percebidas como um processo contínuo após a cirurgia. Assim, aprendemos que a necessidade e o seu atendimento a essas necessidades modificavam-se com o evoluir de seu pós-operatório.

Nesse movimento de reorganização de sua inserção no mundo individual, social e espacial, que as mulheres realizam nos primeiros meses de reabilitação de uma mastectomia, reside um importante papel dos profissionais de saúde e da enfermeira em particular. Há a possibilidade de auxiliá-las na sincronização e interação dessas fases iniciais de forma a favorecer a construção de importantes modelos para elas como expressado: $E$ muito bom você estar aqui para eu conversar, para você posso falar tudo isso, você entende?

Os resultados oferecem importantes elementos para os profissionais compreenderem a mulher que vivencia um pós-operatório de mastectomia por câncer de mama:

Que bom que você apareceu aqui para me ouvir, pois a gente está nervosa, e as pessoas que entram aqui falam que está tudo bem, que é assim mesmo, que tem gente, que já fez a cirurgia há 10 anos. Aí eu paro e pergunto, mas e eu, ninguém vai me ouvir?.

8. Minayo MC. O desafio do conhecimento: pesquisa qualitativa em saúde. 4ª ed. São Paulo (SP): Hucitec-Abrasco; 1996.

9. Goffmann E. Estigma. Notas sobre a manipulação da identidade deteriorada. $4 \stackrel{\text { a }}{ }$ ed. Rio de Janeiro (RJ): Guanabara Koogan; 1988

10. Schilder P. A imagem do corpo: as energias construtivas da psique. São Paulo (SP): Martins Fontes; 1994.

11. Penna L. Corpo sofrido e mal-amado. As experiências da mulher com o próprio corpo. São Paulo (SP): Summus; 1989. 12. Boff L. Saber cuidar Ética do humano - compaixão pela terra. Rio de Janeiro (RJ): Vozes; 1999.

13. Rodrigues JC. O tabu do corpo. Rio de Janeiro (RJ): Vozes; 1983.

14. Foucault M. História da sexualidade 3 - O cuidado de si. Rio de Janeiro (RJ): Graal; 1985.

15. Abeche AM, Blochtein CA. Síndrome do seio fantasma. Femina 1986 abril; 14(4):343-5. 